Commun. Fac. Sci. Univ. Ank. Ser. A1 Math. Stat.

Volume 68, Number 2, Pages 1709-1723(2019)

DOI: $10.31801 /$ cfsuasmas. 443670

ISSN 1303-5991 E-ISSN 2618-6470

http://communications.science.ankara.edu.tr/index.php?series=A1



\title{
PORTFOLIO SELECTION BASED ON A NONLINEAR NEURAL NETWORK: AN APPLICATION ON THE ISTANBUL STOCK EXCHANGE (ISE30)
}

\author{
ILGIM YAMAN AND TÜRKAN ERBAY DALKILIÇ
}

\begin{abstract}
Portfolio optimization is frequently used method for the best portfolio selection, according to some objective. Heuristic techniques designed for solving a problem finding an approximate solution when classic methods fail to find any exact solution, have often used in portfolio selection problem. However, almost none of these techniques used a neural network to allocate the proportion of stocks. The main goal of portfolio optimization problem is minimizing the risk of portfolio while maximizing the expected return of the portfolio. This study tackles a neural network in order to solve the portfolio optimization problem. The data set is the daily price of Istanbul Stock Exchange-30 (ISE30) from May 2015 to May 2017. This study uses Markowitz's Mean-Variance model. Indeed, the portfolio optimization model is quadratic programming (QP) problem. Therefore, many heuristic methods were used to solve portfolio optimization method such as particle swarm optimization, ant colony optimization etc. In fact, these methods do not satisfy stock markets demands in the financial world. This study proposed a nonlinear neural network to solve the portfolio optimization problem. In the implementation phase, the proposed method for portfolio optimization problem has more effective results than present methods.
\end{abstract}

\section{INTRODUCTION}

Portfolio optimization problem is a very prominent issue in the financial world. Up to 1950's, traditional portfolio approach was dealing with just minimizing risk. Harry Markowitz had proposed modern portfolio theory $[1,2]$ which is the kernel of portfolio optimization. In this problem, the main goal is that while maximizing the expected return, in the meanwhile risk of portfolio is minimizing. Markowitz's portfolio optimization problem is denominated mean-variance model. Indeed, the mean-variance model serves to estimate the proportion of stocks that investors

Received by the editors: July 13, 2018; Accepted: December 24, 2018.

2010 Mathematics Subject Classification. Primary 05C38, 15A15; Secondary 05A15, 15A18.

Key words and phrases. Portfolio optimization, nonlinear neural network, Markowitz meanvariance model.

(C)2019 Ankara University Communications Faculty of Sciences University of Ankara-Series A1 Mathematics and Statistics 
will buy and hold. However, the optimization method is not sufficient for today's finance world. The main problem is solving a large-scale quadratic programming problem. Actually, this problem is an NP-hard (non-deterministic polynomial time hardness) problem which requires long computing time. Konno and Yamazaki [3] replace risk function in Markowitz mean-variance model with the absolute deviation of risk function and formulates a mean absolute deviation portfolio optimization model. Many models are generated based on Markowitz mean-variance model. Mean-Var model is proposed by Jorion [4]. Simaan [5], compares the mean-variance model with the mean absolute deviation model. Moreover, Rockafellar and Uryaser [6], studied mean-cvar model. Yan [7] proposed multi-period semi-variance model. Junhui et al. [8], presented nonlinear futures hedging model based on skewness risk and kurtosis risk. These models which owing to probability theory, need the exact estimation: mean of return, variance, and covariance.

In operational research, Konno and Wijayanayake [9] proposed a branch and bound algorithm for calculating the optimal solution of a portfolio selection problem under concave transaction costs and minimal transaction unit constraints. For the portfolio selection algorithm, Lai et al. [10] used a double-stage genetic. Chen and Yaotang [11] suggested a partitioned portfolio insurance strategy and a relational genetic algorithm centered relational encoding to optimize the new partitioned portfolio insurance strategy. Charpentier and Oulidi [12] proposed a simple method to estimate the optimal allocation based on a Value-at-Risk minimization constraint, in addition, it derives empirical-confidence intervals. Juan [13] considered portfolio optimization algorithm for multi-objective planning. Presented method formed genetic algorithm with multi-objective optimization portfolio planning system. Yutao et al. [14] offered a memetic immune algorithm for multi-objective optimization by introducing the pareto dominance which is based on descent operator and the differential evolution operator. Jie et al. [15] presented an optimization model of microgrid multi-objective economic dispatch that adopted the maximum fuzzy satisfaction degree method in order to alter the multi-objective optimization problem to a non-linear single-objective optimum problem.

After developing in the fuzzy set theory, the fuzzy theory has been used in the many portfolio optimization research. Yong et al. [16] represent a bi-objective mixed project portfolio selection model and a fuzzy mixed projects and securities portfolio optimization model. Jiuping et al. [17] proposed an integrated fuzzy random portfolio selection model with a chance constraint. Thus, the developed model consists of fuzzy random returns and the equivalent partitions of two types of chance constraints.

In order to solve QP problems, simplex method, interior point method, active set method and gradient projection method are commonly preferred. These methods could not meet real-life requirements beside require much computational time and cost. In 1985, in order to solve linear programming problem, Tank and Hopfield [18] proposed recurrent neural network based on a gradient method. The major 
advantage of this method is its implementation by using analog electronic circuits. These circuits operate in parallel, which leads to minimizing computational time. That study pioneered the neural network models. Kennedy and Chua [19] proposed a method based on Karush-Kuhn-Tucker conditions which guaranteed convergence. However, this method merely gives an approximated optimal solution. Maa and Schanblatt [20] developed a two-phase model that meets the exact solution. Unfortunately, their model which is relatively complex requires a careful system parameter selection. Zhang and Constantinides [21] invented the lagrangian programming neural network. In this method, dummy variables are presented as new variables in order to cope with inequality constraints. Resulting variables bring about the high dimension which have need for more computation. Dissimilarly, Wang [22] added a time-variant variable to the neural network to solve the linear programs. Xia [23] overcomes all these obstacles by solving primal and dual problems simultaneously. In 2000, Nguyen [24] presented a recurrent neural network model having Xia's models advantages. Moreover, it has faster convergence rate and a more intuitive economic interpretation. In 2014, QP problems can solve with the improved model proposed by Yan [25].

Portfolio optimization model as a backbone of the finance theory whose neural networks are used to plot efficient frontier associated with the portfolio selection problem [26]. Recently, the neural network has been frequently used in financial expectations. Bohra [26] classified stocks with a membership of expected returns.

In this study, proposed the neural network is adapted to solve portfolio optimization problem by solving primal and dual problems simultaneously. In this respect, we use ISE-30 dataset to solve the nonlinear neural network. This paper is organized as: In section 2, portfolio selection is given. In section 3, recurrent nonlinear neural network is described. In section 4, we propose a nonlinear neural network algorithm for solving portfolio selection problem. In Section 5, we present some experimental results. In Section 6, we finish with some discussion.

\section{PORTFOLIO SELECTION}

The trade-off between risk and expected return is a very important issue for the investors. Standard portfolio optimization is presented in 1959 by Markowitz. The main purpose of this problem is to minimize risk while ensuring that the portfolio has an expected return of $R^{*}$ and that the proportions sum to one. Standard portfolio optimization determines stocks proportions $\left(x_{i}: i=1,2, \ldots, N\right)$ where $\mathrm{N}$ indicates number of stocks that investors could be selected. The standard portfolio optimization problem is a nonlinear programming model that is shown by Eq. (1).

$$
\min \sum_{i=1}^{N} \sum_{j=1}^{N} x_{i} x_{j} \sigma_{i j}
$$




$$
\begin{gathered}
\sum_{i=1}^{N} x_{i}=1 \\
\sum_{i=1}^{N} x_{i} \mu_{i}=R^{*} \\
0 \leq x_{i} \leq 1, \quad i=1, \ldots, N
\end{gathered}
$$

Expected return of portfolio, risk of portfolio and Sharpe Ratio denotes with respectively;

$$
E\left(R_{p}\right)=\sum_{i=1}^{N} x_{i} \mu_{i} \quad \sigma_{p}=\sqrt{\sum_{i=1}^{N} \sum_{j=1}^{N} x_{i} x_{j} \sigma_{i j}} \quad S_{p}=\frac{E\left(R_{p}\right)-R_{f}}{\sigma_{p}}
$$

where $\mathrm{N}$ is the number of assets in the portfolio, $\mu_{i}$ presents expected return of the $i^{t h}$ asset. $\sigma_{i j}$ is the correlation between the $i^{t h}$ and $j^{\text {th }}$ assets and $x_{i} ; i^{t h}$ assets' proportion of being in the portfolio. $\mathrm{R}^{*}$ is the expected return in the portfolio. $R_{f}$ is the risk-free rate of return. The main goal is that getting a proportion of assets' being in the selected portfolio $\left(x_{i}\right)$. One of the methods that solves this nonlinear programming problem is a nonlinear neural network.

\section{NONLINEAR NEURAL NETWORK}

Nguyen [24] presented a nonlinear neural network for solving linear programming models. Nguyen's network solves the primal problem and dual problem simultaneously. Fig. 1 [24] demonstrates the configuration of a primal neuron.

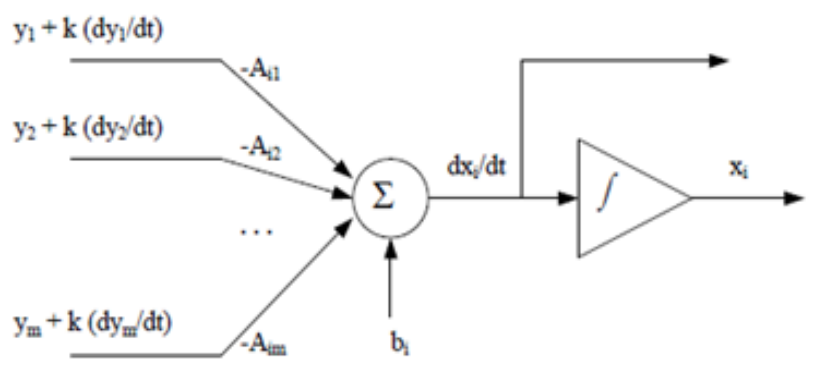

FiguRE 1. Structure of primal neuron.

The nonlinear neural network consists of two layers. One of that is primal neuron and the other one is dual neuron. Inputs of primal neurons are outputs of dual neurons and derivatives. Similarly, inputs of dual neurons are outputs of primal neuron and their derivatives. In contrast to Tank and Hopfield's [18] 
proposed algorithm, Nyguyen's neural networks' neurons is symmetric. Structure of the nonlinear neural network is shown in Fig.2 [24]. The improvement in this method is not only dual neurons is taken an input of model but also their derivatives. This structures ensure nonlinearity into system. The dual neurons have a similar configuration. Nguyen's neural network is extended by Yan [25] in order to solve quadratic programming problems. Background information is given in such articles [23-30].

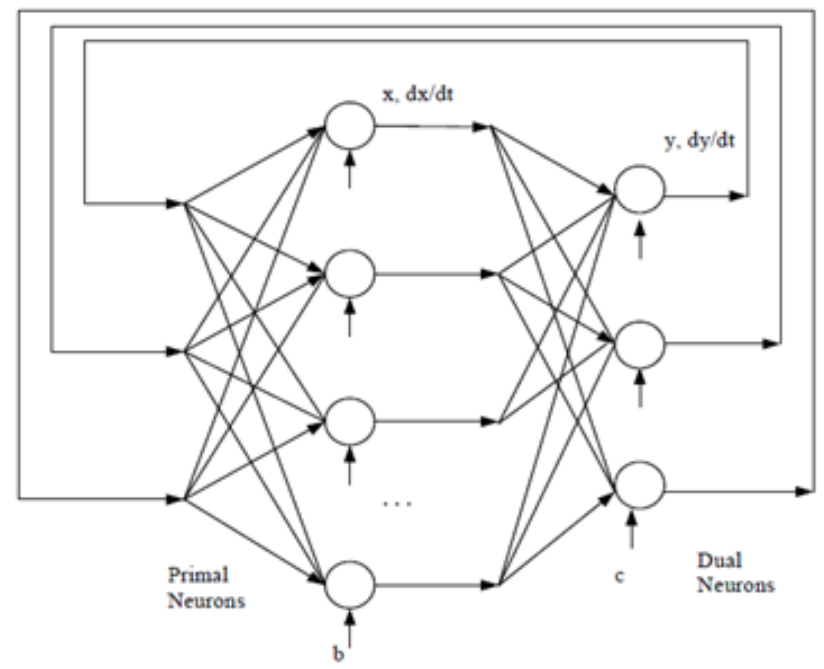

FiguRE 2. Topology of neural network

Consider the QP problem is given by Eq. (3).

$$
\begin{aligned}
& \operatorname{Min} \frac{1}{2} x^{T} Q x+e^{T} x, \\
& D x=b, \\
& A x \geq c, \\
& x \geq 0
\end{aligned}
$$

$x$ and $e$ are $n$-dimensional vectors, $Q$ is an $n \times n$ symmetric positive definite matrix, $D \in R^{p \times n}, A \in R^{m \times n}, b \in R^{p \times 1}, c \in R^{m \times 1}$ The Lagrangian function of this minimization problem can be written as

$$
\mathcal{L}(x, y, z)=\frac{1}{2} x^{T} Q x+e^{T} x-y^{T}(D x-b)-z^{T}(A x-c)
$$

where $z \in R_{+}^{p}=\left\{z \in R^{p} \mid z \geq 0\right\} y \in R^{m}$ are Lagrangian multipliers. According to Karush-Kuhn-Tucker (KKT) conditions, $x^{*}$ is a solution of Lagrangian function 
given by Eq. (4) if there exists $y^{*} \in R^{m}, z^{*} \in R_{+}^{p}$ so that $\left(x^{*}, y^{*}, z^{*}\right)$ satisfies the conditions which are given by Eq. (5):

$$
\begin{aligned}
& Q x^{*}+e-D^{T} y^{*}-A^{T} z^{*} \geq 0, \\
& x^{* T}\left(Q x^{*}+e-D^{T} y^{*}-A^{T} z^{*}\right)=0, \\
& b-D x^{*}=0, \\
& c-A x^{*} \leq 0, \\
& z^{* T}\left(c-A x^{*}\right)=0 .
\end{aligned}
$$

Yan [25] proposed the recurrent neural network for solving quadratic programming problem given in Eq. (6).

$$
\begin{aligned}
& \dot{x}=-Q(x+k \dot{x})-e+D^{T}(y+k \dot{y})+A^{T}(z+k \dot{z}), x \geq 0, \\
& \dot{y}=b-D(x+k \dot{x}), \\
& \dot{z}=-A(x+k \dot{x})+c, z \geq 0,
\end{aligned}
$$

\section{NONLINEAR NEURAL NETWORK FOR PORTFOLIO OPTIMIZATION PROBLEM}

Standard portfolio optimization problem is a simple nonlinear programming problem. Indeed, the main goal is minimizing risk while ensuring that $\mathrm{R}$ is the expected return of the portfolio and the total proportion of stocks equals to one. Nonlinear neural network solves nonlinear programming problems. Primal and dual problems which are nonlinear programing problems solved simultaneously. Outputs of dual neurons and their derivatives are the inputs of primal neurons, similarly the primal neuron's outputs and derivatives are the inputs of dual neurons and their derivatives. This paper proposed a neural network in order to solve portfolio optimization problem is given in Eq. (7a-c). The topology of this neural network is given by Fig. 3 .

$$
\begin{aligned}
& \dot{x}=-2 \sigma(x+k \dot{x})+[1,1, \ldots 1]^{T}(y+k \dot{y})+\mu^{T}(z+k \dot{z}), x>0 \\
& \dot{y}=[1,1 \ldots 1]-[1,1 \ldots 1](x+k \dot{x}) \\
& \dot{z}=-\mu(x+k \dot{x})+R, \quad z>0
\end{aligned}
$$

Proposed algorithm:

Step1: Initialize the $x=\{0\}, y=\{0,1,2,3\}, z=\{-1,0,1,2\}$ and $d x, d y$, and $d z$ as a zeros vectors.

Step2: Assignee mean and variance of stocks to the corresponding variables $\mu, \sigma$.

Step3: Calculate first node in order to get $(x+k \dot{x})$ 


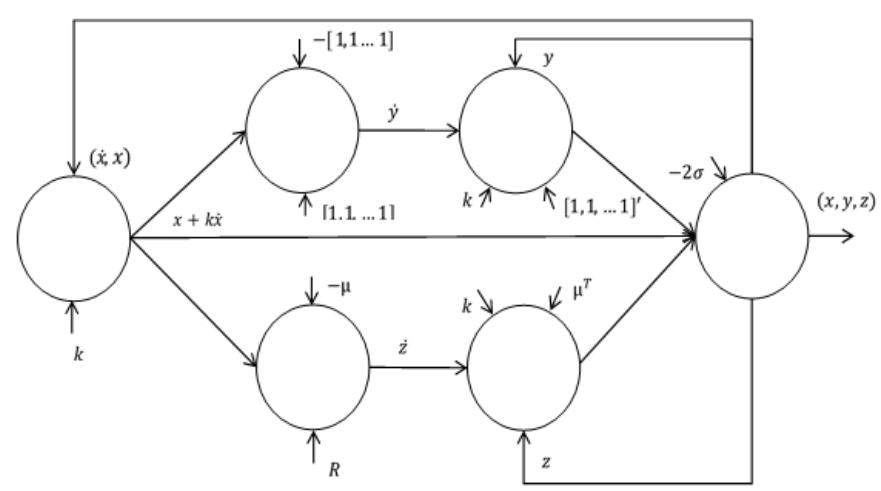

FIgURE 3. Topology of neural network for solving portfolio optimization

Step4a: Take first node's output as an input to calculate $\dot{y}$ as an output by using Eq. (7b).

Step4b: Take first node i.e $(x+k \dot{x})$ in order to calculate output $z$. by using Eq. (7c).

Step5a:Take $\dot{y}$ and $y$ as an input in order to calculate node i.e $(y+k \dot{y})$.

Step5b:Take $\dot{z}$ and $z$ as an input in order to calculate node i.e $\mu^{T}(z+k \dot{z})$.

Step6: Calculate $\dot{x}$ by using former nodes outputs as an input of the last node by using Eq. (7a).

Step7: If termination criteria are satisfied, go to Step 8 if not satisfied go to Step 3.

Step8: Calculate expected return, risk and Sharpe ratio of the portfolio with selected proportions of $x_{i}$ by using Eq. (2).

\section{Computational Experiments}

In this section, we present the results obtained nonlinear neural network that solved portfolio optimization problem. The test data which is Istanbul Stock Exchange 30 data were obtained from https://tr.investing.com/.com. This data corresponds to daily prices between June 2015 and May 2017 which is totally 480 days. There are 30 different stocks whose abbreviations are given by Table- 4 in Appendix. To indicate advantages and effectiveness of proposed algorithm, comparison is done between heuristic and traditional methods. The traditional method which is 
active set method to solve quadratic optimization problem is an iterative method that solves a sequence of equality-constrained quadratic problems. This method consists of two phase. In the first phase, objective is ignored while feasible point found for the constraints. In the second phase the objective is minimized while feasibility is maintained. The active set method had frequently used to solve portfolio optimization problem. In order to solve portfolio optimization problem by the active set method, 'optimoptions' function is used in MATLAB2014b whereas the proposed algorithm given in Section-4 be programmed in MATLAB2014b.

The covariance matrix $\sigma_{30 \times 30}$ and the mean vector $\mu_{30 \times 1}$ of ISE-30 stocks are calculated as;

$$
\sigma=\left(\begin{array}{cccccc}
0.00034056 & 0.0001635 & 0.00013038 & 0.00011224 & \ldots & 0.00028666 \\
0.00016350 & 0.00032489 & 0.00098450 & 0.00010401 & \ldots & 0.00016158 \\
0.00013038 & 0.00098945 & 0.00033762 & 0.00078248 & \ldots & 0.00013672 \\
\ldots & \ldots & \ldots & \ldots & \ldots & \ldots \\
0.0002866 & 0.0001615 & 0.00013677 & 0.0001115 & \ldots & 0.00035471
\end{array}\right)
$$

$$
\mu=\left(\begin{array}{c}
0.000665 \\
0.001305 \\
0.002515 \\
0.000546 \\
0.000650 \\
0.001745 \\
0.000466 \\
\ldots \\
0.000778 \\
0.000943 \\
0.000366
\end{array}\right)
$$

The portfolio optimization problem fitness function $f(x)$ based on $\sigma$ and $\mu$ given by Eq. (8).

$$
\begin{aligned}
& \operatorname{minf}(x)=x_{1}^{2} 0.00034056+2 x_{1} x_{2} 0.0001635+2 x_{1} x_{3} 0.00013038+\ldots \\
& +x_{30}^{2} 0.00035471 \\
& x_{1}+x_{2}+\cdots+x_{30}=1 \\
& x_{1} 0.0066+x_{2} 0.0013+x_{3} 0.0025+x_{4} 0.0005+\cdots+x_{30} 0.004 \geq 0.002 \\
& 0 \leq x_{i} \leq 1, \quad i=1,2, \ldots, 30
\end{aligned}
$$

where; $x_{i}$ : proportion of $i^{\text {th }}$ stock.

The expected return of the portfolio calculated by the Eq. (9).

$$
E\left(R_{p}\right)=x_{1} 0.00065+x_{2} 0.001305+\cdots+x_{30} 0.000366
$$


The Risk of Portfolio Calculated by the Eq. (10).

$$
\sigma_{p}=\sqrt{x_{1}^{2} 0.00034056+2 x_{1} x_{2} 0.0001635+2 x_{1} x_{3} 0.00013038+\cdots+x_{30}^{2} 0.00035471}
$$

The Sharpe Ratio of the Portfolio Calculated by the Eq. (11)

$$
S_{p}=\frac{x_{1} 0.00065+x_{2} 0.001305+\ldots+x_{30}-0}{\sqrt{x_{1}^{2} 0.00034056+2 x_{1} x_{2} 0.0001635+2 x_{1} x_{3} 0.00013038+\ldots+x_{30}^{2} 0.00035471}}
$$

According to the principle of superiority, low risky investment will be selected in which investments have the same variance. Moreover increasing in expected return leads to increase the risk in the portfolio. Expected return, the risk of the portfolio and the fitness function $(f(x))$ is given for the different initial value of $y$ and $z$ are given in Table 1.

TABLE 1. Expected return, risk and fitness function value of portfolio for

\begin{tabular}{|c|c|c|c|c|c|c|}
\hline $\begin{array}{c}\text { Initial } \\
y\end{array}$ & $\begin{array}{c}\text { Values } \\
z\end{array}$ & $\begin{array}{c}\text { Iteration } \\
\text { Number } \\
n\end{array}$ & $\begin{array}{c}\text { Expected } \\
\text { Return } \\
\mu\end{array}$ & $\begin{array}{c}\text { Risk } \\
\sigma \\
\end{array}$ & $\begin{array}{c}\text { Sharpe } \\
\text { Ratio } \\
S_{p}\end{array}$ & $\begin{array}{c}\text { Fitness } \\
\text { function } \\
f(x)\end{array}$ \\
\hline 0 & 1 & 260 & 0.001945 & 0.012035 & 0.16156 & 0.00014485 \\
\hline 1 & 0 & 440 & 0.002033 & 0.012354 & 0.16215 & 0.00015265 \\
\hline 1 & 1 & 440 & 0.0020034 & 0.012355 & 0.16216 & 0.00015265 \\
\hline 0 & 0 & 200 & 0.0017735 & 0.011793 & 0.15039 & 0.00013908 \\
\hline 1 & -1 & 442 & 0.0019992 & 0.012306 & 0.16246 & 0.00015144 \\
\hline 1 & 2 & 440 & 0.0020037 & 0.012355 & 0.16218 & 0.00015265 \\
\hline 2 & -1 & 456 & 0.0020177 & 0.012946 & 0.15585 & 0.00016761 \\
\hline 2 & 1 & 491 & 0.0020006 & 0.012354 & 0.16238 & 0.00015262 \\
\hline 0 & 2 & 170 & 0.0017300 & 0.011206 & 0.15439 & 0.00012557 \\
\hline 3 & 1 & 500 & 0.0020123 & 0.012652 & 0.15905 & 0.00016008 \\
\hline 3 & -1 & 500 & 0.0020123 & 0.012652 & 0.15905 & 0.00016007 \\
\hline
\end{tabular}
different initial value of $(y, z)$

As shown in Table 1, for the different initial value of $y$ and $z$ nearly same stocks are selected. Firstly, selected a portfolio has the minimum fitness function value $f(x)=(0.00012557)$ which has initial values: $y=0, z=2$. Shape ratio indicates how much additional return investors earn by taking additional risk. A portfolio with a higher Sharpe ratio is considered superior to theirs. When the initial values are $y=1, z=-1$, the highest Sharpe ratio is obtained $(S p=0.16246)$. Each stock change in proportion is given in Fig. 4 with different colors. Also, fitness functions for the two different initial point that form the curves in Fig. 5. As shown in Table 2 , the initial points are $y=0, z=2$, Nine stocks are selected for the first portfolio which are composed of $0.03 \%$ As shown in Table 2, the initial points are $y=0$, $z=2$, Nine stocks are selected for the first portfolio which are composed of 0.03 

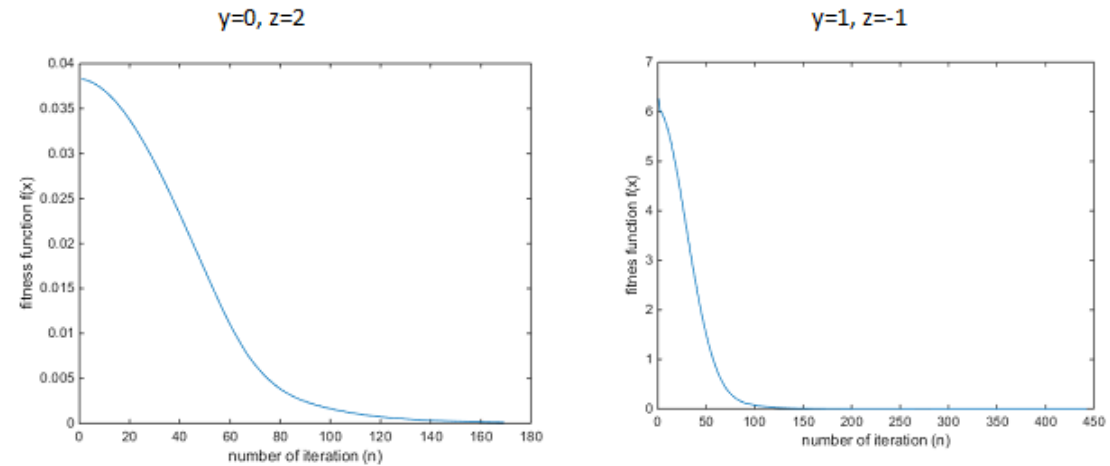

FiguRE 4. Allocation of stocks' proportion for different initial values of $y, z$
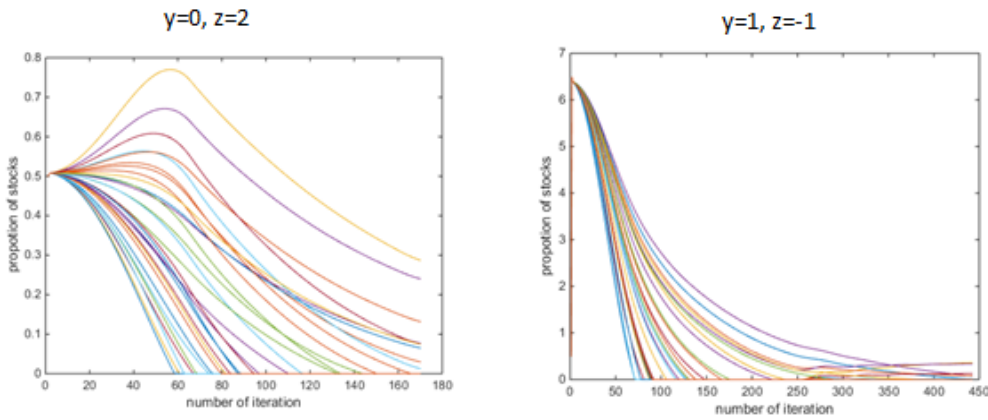

FiguRE 5. Fitness function graphs for different initial values of $y, z$

\% ARCLK, $0.28 \%$ ASELS, $0.08 \%$ BIMAS, $0.01 \%$ ECICL, $0.07 \%$ ENKAI, 0.13 \% OTKAR, $0.24 \%$ PETKM, $0.08 \%$ TEKFN, $0.08 \%$ TUPRS stocks. When the initial points are $y=1, z=-1$, seven stocks are selected $0.35 \%$ ASELS, $0.07 \%$ BIMAS, $0.02 \%$ ECICL, $0.01 \%$ ENKAI, 0.08 \% OTKAR, $0.34 \%$ PETKM, $0.13 \%$ TEKFN. 
TABle 2. Proportions of selected stocks

\begin{tabular}{ccc}
\hline Name of Stocks & $\begin{array}{c}\text { Proportion } \\
\text { for } y=0, z=2\end{array}$ & $\begin{array}{c}\text { Proportion } \\
\text { for } y=1, z=-1\end{array}$ \\
\hline ARCLK & 0.03 & 0 \\
ASELS & 0.28 & 0.35 \\
BIMAS & 0.08 & 0.07 \\
ECILC & 0.01 & 0.02 \\
ENKAI & 0.07 & 0.01 \\
OTKAR & 0.13 & 0.08 \\
PETKM & 0.24 & 0.34 \\
TEKFN & 0.08 & 0.13 \\
TUPRS & 0.08 & 0 \\
\hline
\end{tabular}

TABLE 3. Proportions of selected stocks by nonlinear neural network and active set method

\begin{tabular}{ccc}
\hline $\begin{array}{c}\text { Name of } \\
\text { Stocks }\end{array}$ & $\begin{array}{c}\text { Active } \\
\text { Set Method }\end{array}$ & $\begin{array}{c}\text { Non-Linear } \\
\text { Neural Network } \\
\text { (for } y=1, z=-1)\end{array}$ \\
\hline ARCLK & 0.0135 & 0 \\
ASELS & 0.0600 & 0.35 \\
BIMAS & 0.1869 & 0.07 \\
DOHOL & 0.0368 & 0 \\
ECILC & 0 & 0.02 \\
ENKAI & 0.1514 & 0.01 \\
OTKAR & 0.1065 & 0.08 \\
PETKM & 0.1267 & 0.34 \\
TKFEN & 0.0210 & 0.13 \\
TUPRS & 0.1019 & 0 \\
TTKOM & 0.0780 & 0 \\
TCELL & 0.1173 & 0 \\
\hline Expected & & 0.00200 \\
Return & 0.00094 & 0.01231 \\
\hline Risk & 0.01000 & 0.16246 \\
\hline Sharpe & & 0.00015 \\
Ratio & 0.09400 &
\end{tabular}

As shown in Table 3, the results of active set method and proposed method (for $y=1, z=-1$ ) which has a highest Sharpe Ratio are compared. While active set method selects eleven stocks in order to invest money, the nonlinear neural network selects seven stocks. The selected stocks by active set method are $0.01 \%$ ARCLK, $0.06 \%$ ASELS, $0.19 \%$ BIMAS, $0.04 \%$ DOHOL, $0.15 \%$ ENKAI, $0.10 \%$ OTKAR, 
$0.12 \%$ PETKM, $0.02 \%$ TKFEN, $0.11 \%$ TUPRS, $0.08 \%$ TTKOM, $0.12 \%$ TCELL. The expected return of portfolio which is selected by active set method 0.00094, risk of the portfolio 0.01 and Sharpe Ratio is 0.094. Although the variances (risk) of the selected portfolios are quite similar, the proposed method, for $y=1, z=1$, gets high expected return (0.002), then active set method (0.00094). Based on Sharpe Ratio criteria, selected portfolio with neural network is superior to other portfolios.

\section{Discussion}

In this paper, we proposed a nonlinear neural network to solve portfolio selection problem. Proposed algorithm has been run for different initial value of $y$ and $z$. It is seen that the number of selected stocks differ when using different starting values. The initial points $(y=1, z=-1)$ gives best Sharpe Ratio and it is selected seven stocks. Then the proposed method is compared with the traditional method, active set method. The ISE-30 data is used for the comparison of nonlinear neural network and active set method that is frequently used for solving quadratic optimization problems such as portfolio optimization problem. The remarkable distinction is that the nonlinear neural network has greater expected return than active set method while having the relatively same risk. The Sharpe Ratio shows that selected portfolios have relatively same risk, but proposed algorithm for portfolio selection problem has higher expected return than the active set method. As a result of these experiments nonlinear neural network to solve portfolio optimization model can be assumed as a powerful model.

\section{REFERENCES}

[1] Markowitz, H., Portfolio Selection, Journal of finance, (1952).

[2] Markowitz, H., Portfolio selection efficient diversification of investment, Newyork Wiley, 1959.

[3] Konno, H. and Yamazaki, H., Mean absolute portfolio optimisation model and its application to Tokyo stock market, Management Science 37 (5), (1991), 519-531.

[4] Jorion, P.H., Value at Risk: A New Benchmark for Measuring Derivatives Risk, Chicago: Irwin Professional Publishers, 1996.

[5] Simaan, Y., Estimation risk in portfolio selection: The mean variance model and the meanabsolute deviation model, Management Science, 43, (1997), 1437-1446.

[6] Rockafellar T.R. and Uryaser S.P., Optimization of Conditional Value-at-risk, J. Risk, 2, (2000), 21-41.

[7] Yan, W. and Li, S., A Class of Multi-period Semi-variance Portfolio Selection with a Fourfactor Futures Price Model, J. Appl. Math. Comput, 29, (2009), 19-34.

[8] Junhui, F., Weiguo, Z., Qian, L. and Qin, M., Nonlinear Futures Hedging Model Based on Skewness Risk and Kurtosis Risk, Systems Engineering, 27(10), (2009), 44-48.

[9] Konno, H. and Wijayanayake, A. Portfolio Optimization Problem Under Concave Transaction Costs and Minimal Transaction Unit Constraints, Math. Program, 89, (2001), 233-250.

[10] Lai, K. K., Yu, L., Shouyang, W. and Chengxiong, Z., A Double-Stage Genetic Optimization Algorithm for Portfolio Selection, International Conference on Neural Information Processing, 4234, (2006), 928-937.

[11] Chen, J.S. and Yaotang, L., A Partitioned Portfolio Insurance Strategy by Relational Genetic Algorithm, Lecture Notes in Artificial Intelligence, 4304, (2006), 857-866. 
[12] Charpentier, A. and Oulidi, A., Estimating Allocations for Value-at-risk Portfolio Optimization, Mathematical Methods of Operations Research, 69, (2009), 395-410.

[13] Juan, C., Portfolio Optimization Algorithm for Multi Objective Programming, Xian: Xi'an Shiyou University, (2012), 16-42.

[14] Yutao, Q., Fang, L., Weiyuan, C., Xiaoliang, M. and Licheng, J. Memetic Immune Algorithm for Multi-objective Optimization, Journal of Software, 24(7) (2013), 1529-1544.

[15] Jie, C., Xiu, Y., Lan, Z., Meixia, Z. and Zhenkun, L., Microgrid Multi-objective Economic Dispatch Optimization, Proceedings of the CSEE, 33(19), (2013), 57-66.

[16] Yong, F., Lai, K. and Yangshou, W., A Fuzzy Mixed Projects and Securities Portfolio Selection Model, Lecture Notes in Artificial Intelligence, 3614, (2005), 931-940.

[17] Jiuping, X., Xiaoyang and Z., Li, S., A Class of Chance Constrained Multi-objective Portfolio Selection Model Under Fuzzy Random Environment, Journal of Optimization Theory and Applications, 150, (2011), 530-552.

[18] Tank, D. W. and Hopfield, J. J., Simple neural optimization networks: An A/D converter, signal decision circuit, and linear programming circuit, IEEE Transactions on Circuits and Systems, 33(5), (1986), 533-541.

[19] Kennedy, M.,P. and Chua, L.O., Neural network for nonlinear programming, IEEE Transactions on Circuits and Systems, 35 (5), (1988),554-562.

[20] Maa, C. Y. and Schanblatt, M.A., A two-phase optimization neuralnetwork, IEEE Transactions on Neural Network 3 (6), (1992), 1003-1009,.

[21] Zhang, S. and Constantinides, A. G., Lagrange programming neural networks, IEEE Transactions on Circuits and Systems, II 39 (7), (1992), 441-445.

[22] Wang, J., A deterministic annealing neural network for convex programming, Neural Networks 5 (4), (1994),962-971.

[23] Xia, Y., A new neural network for solving linear programming problems and its application, IEEE Transactions on Neural Networks, (1996).

[24] Nyguen, K.V., A Nonlinear Network for Solving Linear Programming Problem s., International Symposium on Matematical Programming, ISMP, Atlanta, GA, USA, (2000).

[25] Yan, Y., A new nonlinear neural network for solving QP problems. Springer International Publishing Switzerland, 347-357,(2014).

[26] Bohra, D. and Bhatia, S., Portfolio Return Modelling Using ANFIS, International Journal of Engineering Research 83 Technolog, (2012).

[27] Malek, A., and Yari, A., Primal' dual solution for the linear programming problems using neural networks, Applied Mathematics and Computation 167,1, (2005), 198-211.

[28] Malek, A., Applications of Recurrent Neural Networks to Optimization Problems. Recurrent Neural Networks In Tech., (2008).

[29] Yan, Y. A Nonlinear Neural Network's Stability Analysis and Its kWTA Application, International Symposium on Neural Networks, Springer, Cham, (2015).

[30] Xia, Y., Neural network for solving extended linear programming problems. IEEE transactions on neural networks, 8.3, (1997), 803-806. 


\section{Appendix}

TABLE 4. Abbreviation of BIST30 Stocks

\begin{tabular}{cc}
\hline AKBNK & Akbank TAŞ \\
ARCLK & Arçelik AŞ \\
ASELS & Aselsan Elektronik Sanayi ve Ticaret AŞ \\
BIMAS & BIM Birleşik Magazalar AŞ \\
DOHOL & Doğan Şirketler Grubu Holding AŞ \\
ECILC & Eczacıbaşı İlaç Sanayi ve Finansal Yatırımlar Sanayi ve Ticaret AŞ \\
EKGYO & Emlak Konut Gayrimenkul Yatırım Ortakları \\
ENKAI & ENKA İnşaat ve Sanayi AŞ \\
EREGL & Ereğli Demir ve Çelik Fabrikaları TAŞ \\
GARAN & Türkiye Garanti Bankası \\
SAHOL & Hacı Ömer Sabancı Holding AŞ \\
KRDMD & Koc Holding AŞ \\
KCHOL & Koza Altın İşletmeleri AŞ \\
KOZAL & Kardemir Karabuk Çelik Sanayi ve Ticaret AŞ \\
KOZAA & Koza Anadolu Metal Madencilik İsletmeleri AŞ \\
OTKAR & Otokar Otomotiv ve Savunma Sanayi AŞ \\
PGSUS & Pegasus Hava Taşımacıllğı AŞ \\
PETKM & Petkim Petrokimya Holding AŞ \\
SISE & Türkiye Şişe ve Cam Fabrikaları AŞ \\
TAVHL & TAV Havalimanları Holding \\
TKFEN & Tekfen Holding AŞ \\
THYAO & Türk Hava Yolları AO \\
TOASO & Tofas Turk Otomobil Fabrikası AŞ \\
TUPRS & Türkiye Petrol Rafinerileri AŞ \\
TTKOM & Turk Telekominikasyon AŞ \\
TCELL & Turkcell İletişim Hizmetleri AŞ ORD \\
HALKB & Türkiye Halk Bankası \\
ISCTR & Türkiye Is Bankası AS Class C \\
VAKBN & Türkiye Vakıflar Bankası TAO \\
YKBNK & Yapı ve Kredi Bankası AŞ \\
\hline
\end{tabular}


Current address: Ilgim Yaman: Giresun University Faculty of Arts and Sciences Department of Statistics Güre Campus 28200 Giresun TURKEY

E-mail address: ilgimyaman@gmail.com

ORCID Address: https://orcid.org/0000-0002-6070-9279

Current address: Türkan Erbay Dalkılıç: Karadeniz Technical University, Faculty of Science, Statistics and Computer Science, 61080 Trabzon TURKEY

E-mail address: tedalkilic@gmail.com

ORCID Address: https://orcid.org/0000-0003-2923-599X 